\title{
Breeding and Rearing of Sand Goby (Oxyeleotris marmoratus Blk.) Fry*
}

\author{
PANU TAVARUTMANEEGUL ${ }^{1}$ and C. KWEI LIN ${ }^{2}$ \\ 'Pathum Thani Fisheries Development Center, Royal Thai Department of Fisheries, Bangkok \\ (Thailand) \\ ${ }^{2}$ Great Lakes Research Division, The University of Michigan, Ann Arbor, MI 48109 (U.S.A.)
}

Correspondence and reprint requests should be addressed to: C. Kwei Lin, Agricultural and Food Engineering, Asian Institute of Technology, GPO Box 2754, Bangkok (Thailand)

*CRSP/Pond Dynamics Contribution No. 86:10.

(Accepted 3 September 1987)

\begin{abstract}
Tavarutmaneegul, P. and Lin, C.K., 1988. Breeding and rearing of sand goby (Oxyeleotris marmoratus Blk.) fry. Aquaculture, 69: 299-305.

A large-scale experiment on production of sand goby fry was conducted for one annual cycle at Nong-Sua Fisheries Station in Thailand. Approximately 1000 egg nests containing 25 million eggs were collected from January through October from artificial substrates. The hatching rate of fertilized eggs was approximately $80 \%$. Fry were reared in two stages. In stage 1 , the newly developed fry, with average total body length of $4 \mathrm{~mm}$ and mouth size opening of approx. $0.1 \mathrm{~mm}$, were first fed with a combination of chicken-egg slurry and live rotifers. The survival rate for this stage ranged from 7 to $55 \%$, with an average of $20 \%$ among batches of egg nests collected during the year. Older stage 2 fry were fed with live Moina sp., chironomid larvae, and ground raw fish from days 30 to 60 . Stage 2 survival rates ranged from 60 to $99 \%$ and length increased from 2.4 to 3.8 $\mathrm{cm}$. Growth rate was inversely related to stocking density at this stage. A total of 147300 juvenile fish was produced in the 1-year effort.
\end{abstract}

\section{INTRODUCTION}

Sand goby (Oxyeleotris marmoratus Bleeker) is the largest member of the goby family (Smith, 1945). In Thailand, it has been domesticated and cultured in ponds and cages since the early nineteen-seventies (Suwansart, 1979). The total production from cage culture reached 560 tons in 1981 (DOF, 1983). Increasing market demand and high market value (approx. $\$ 10 / \mathrm{kg}$ ) in recent years have resulted in expansion of production systems in Thailand. Subsequently, the supply of fingerlings, traditionally recruited from natural waters, has become limited and imposes a severe deterrent to grow-out production. 
Although the fish have been successfully bred by both natural (Phinal, 1980) and artificial spawning (Tan and Lam, 1973), little effort has been put into fry rearing and few attempts have been made to mass produce stockable size fingerlings.

This paper presents the preliminary results of semi-natural breeding and rearing of sand goby fry on a large scale.

\section{MATERIALS AND METHODS}

\section{Spawning and hatching}

Spawning of sand goby was achieved by stocking 250 and 300 pairs of sexually mature males and females of $300-500$-g size at $1: 1$ sex ratio in each of two $1600-\mathrm{m}^{2}$ earthen ponds, respectively. The sexes of the fish were distinguished by examining their urogenital papillae: the males possess small, flat triangular structures while the females have large finger-shaped protrusions, which become reddish during the spawning season. Broodstock was fed daily with chopped raw fish. To collect the eggs, 20 triangular artificial substrates (Fig. 1), each made of three $30 \mathrm{~cm} \times 30 \mathrm{~cm}$ asbestos tiles, were placed at the bottom along the edges of the pond. Approximately 2 weeks after stocking, the brooders deposited and fertilized eggs on the inner surface of the artificial substrates. The substrates were checked daily for eggs and those plates covered with eggs were transferred to hatchery aquaria for incubation. The number of eggs deposited on each plate was estimated by the area covered by egg masses and the number of eggs $/ \mathrm{cm}^{2}$. Substrates were checked regularly for egg masses throughout the year. The water quality parameters of the brood pond monitored weekly were $\mathrm{pH}$ (by Orion $\mathrm{pH}$ meter), temperature, and dissolved oxygen concentration (by YSI meter).

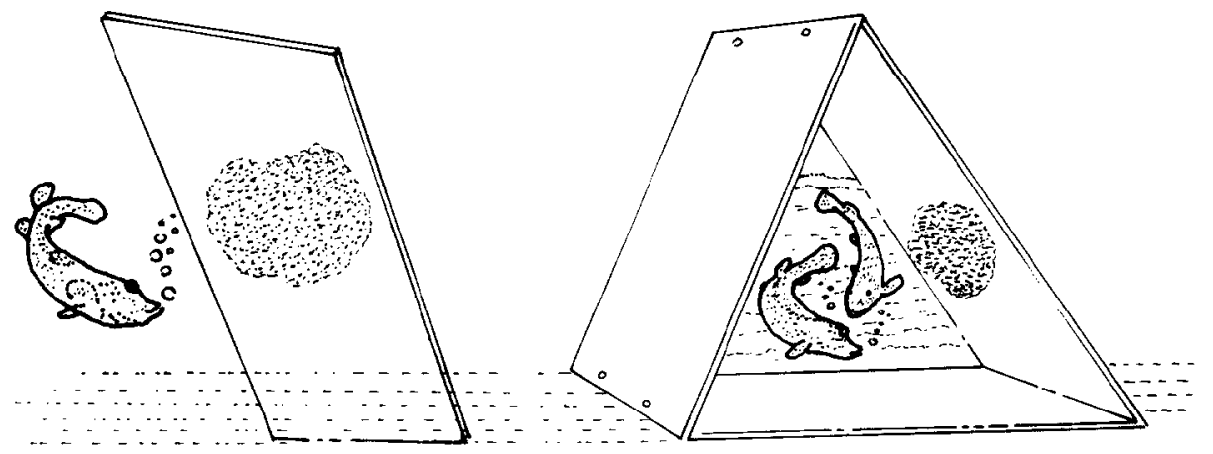

Fig. 1. Schematic diagram of the structure of artificial substrates used for the collection of sand goby eggs. 
TABLE 1

Schedules for the variety of feed used in rearing sand goby fry during the first 60 days

\begin{tabular}{llllll}
\hline & \multicolumn{3}{l}{ Feeding period (days) } \\
\cline { 2 - 5 } & 3 & 7 & 20 & 30 & 60 \\
\hline Egg slurry & $\mathrm{X}$ & $\mathrm{X}$ & & & \\
Rotifers & $\mathrm{X}$ & $\mathrm{X}$ & $\mathrm{X}$ & $\mathrm{X}$ & \\
Moina & & & $\mathrm{X}$ & $\mathrm{X}$ & $\mathrm{X}$ \\
Chironomids & & & & $\mathrm{X}$ & $\mathrm{X}$ \\
Ground trash fish & & & & $\mathrm{X}$ & $\mathrm{X}$ \\
\hline
\end{tabular}

Egg hatching and fry rearing

Eggs adhering to the substrates were incubated in 40-l aquaria, each containing two to three plates placed upright. Each aquarium was continuously aerated by two to three air diffuser stones. Water quality in the fry rearing tanks was maintained as stable as possible with saturated dissolved oxygen, near neutral $\mathrm{pH}$, and moderate hardness. Fertilized eggs hatched in 2-4 days at $26-28^{\circ} \mathrm{C}$. The hatchlings were kept in the hatching tanks for $3-5$ days until their yolk sacs were absorbed. The newly developed fry were then collected from the aquaria and transferred to $6-\mathrm{m}^{2}$ concrete tanks in which the fry were fed with a combination of slightly heated chicken-egg slurry and live rotifers. After 30 days of rearing, the fry were collected, counted, and their weight and length measured prior to transferring them to twelve $50-\mathrm{m}^{2}$ outdoor concrete tanks. In these tanks, the fry were cultured for another 30 days to determine their growth rate and survival under stocking densities of $20,40,80$ and 100 $\mathrm{fish} / \mathrm{m}^{2}$. At this stage, fish were fed with a variety of live feeds (Moina sp., rotifers, chironomid larvae) and ground raw fish. To supply adequate live feed for rearing fry, Moina, rotifers (Brachionus spp.), and chironomid larvae were mass produced (Lin and Tavarutmaneegul, 1985). Table 1 summarizes the schedule for various types of feed used during the initial 60-day rearing period. Survival rate and weight of the fingerlings were determined at the end of the experimental period.

\section{RESULTS}

Environmental conditions of the broodstock pond, monitored weekly throughout the annual cycle, showed: (a) $\mathrm{pH}$ fluctuated between 5.8 and 9.0, with most values measured near 7. Liming was required to prevent drastic $\mathrm{pH}$ changes as the ponds were located in the Thailand central plain where acid sulfate soils prevail ( $\mathrm{Lin}, 1986$ ); (b) dissolved oxygen concentration ranged between 4.5 and $12 \mathrm{mg} / \mathrm{l}$, with most values around $6 \mathrm{mg} / \mathrm{l}$; (c) the monthly 
maximum temperature of pond water ranged from 30 to $35^{\circ} \mathrm{C}$, and the minimum from 21 to $28^{\circ} \mathrm{C}$. The monthly temperature differential fluctuated from 4 to $11^{\circ} \mathrm{C}$, with the greatest range $\left(>8^{\circ} \mathrm{C}\right)$ occurring from November to February.

As indicated by the number of egg nests collected monthly from January through October in the two spawning ponds, sand goby spawned most of the year. Peak activity occurred during May and June; no eggs were collected during November and December (Table 2). The number of egg nests collected from each of the two ponds in 1 year totalled 502 and 551, with annual average of 3.3 and 4.4 egg nests per female, respectively. During the active spawning period (February-September), an average of $60+$ egg nests was collected monthly from each pond in which $125-150$ female brooders resided. It is estimated that each female spawned at least three times annually.

Fecundity per spawn, based on number of eggs deposited on each substrate per collection, varied between 2000 and 30000 eggs. Eggs were embedded in circular, jelly-like, translucent masses with an average area of $250-350 \mathrm{~cm}^{2}$. With an average of $24000 \mathrm{eggs} / \mathrm{nest}$, it was estimated that 25 million eggs were collected in the 1-year experimental cycle.

Fertilized eggs incubated in aquaria hatched in 2-4 days depending on the water temperature, which varied between 26 and $30^{\circ} \mathrm{C}$ during the spawning season. Individual eggs of the same nest also exhibited considerable variation in hatching time. Over $80 \%$ of the fertilized eggs hatched. The newly hatched larvae, average total length of approximately $3 \mathrm{~mm}$, possessed unpigmented yolk sacs, and undeveloped jaws and digestive tracts. During the larval development stage, mortality was estimated as high as $90 \%$. After $4-5$ days, the surviving larvae absorbed their yolk sacs and the transformed fry were capable of swimming and feeding. Approximately 750000 fry reached the first feeding phase. At this stage, the average body length of fry was $4 \mathrm{~mm}$ and mouth size openings were approximately $0.08-0.2 \mathrm{~mm}$.

During the first 30 days of rearing, the fry grew to an average length of $1 \mathrm{~cm}$, with survival rate ranging from 7 to $55 \%$ (average 20\%) among 30 rearing

TABLE 2

Number of egg nests collected each month throughout the annual cycle, and average number of nests produced per female

\begin{tabular}{lllllllllllllllllll}
\hline Pond & $\begin{array}{l}\text { No. } \\
\text { brooders }\end{array}$ & \multicolumn{10}{ll}{ Egg nests collected monthly } \\
\cline { 2 - 13 } & J & F & M & A & M & J & J & A & S & O & N & D & Total & $\begin{array}{l}\text { Nests/ } \\
\text { female }\end{array}$ \\
\hline A & 300 & 1 & 68 & 54 & 67 & 70 & 69 & 61 & 60 & 52 & 20 & 0 & 0 & 502 & 3.3 \\
B & 250 & 32 & 57 & 52 & 54 & 76 & 78 & 45 & 52 & 40 & 25 & 0 & 0 & 551 & 4.4 \\
\hline
\end{tabular}




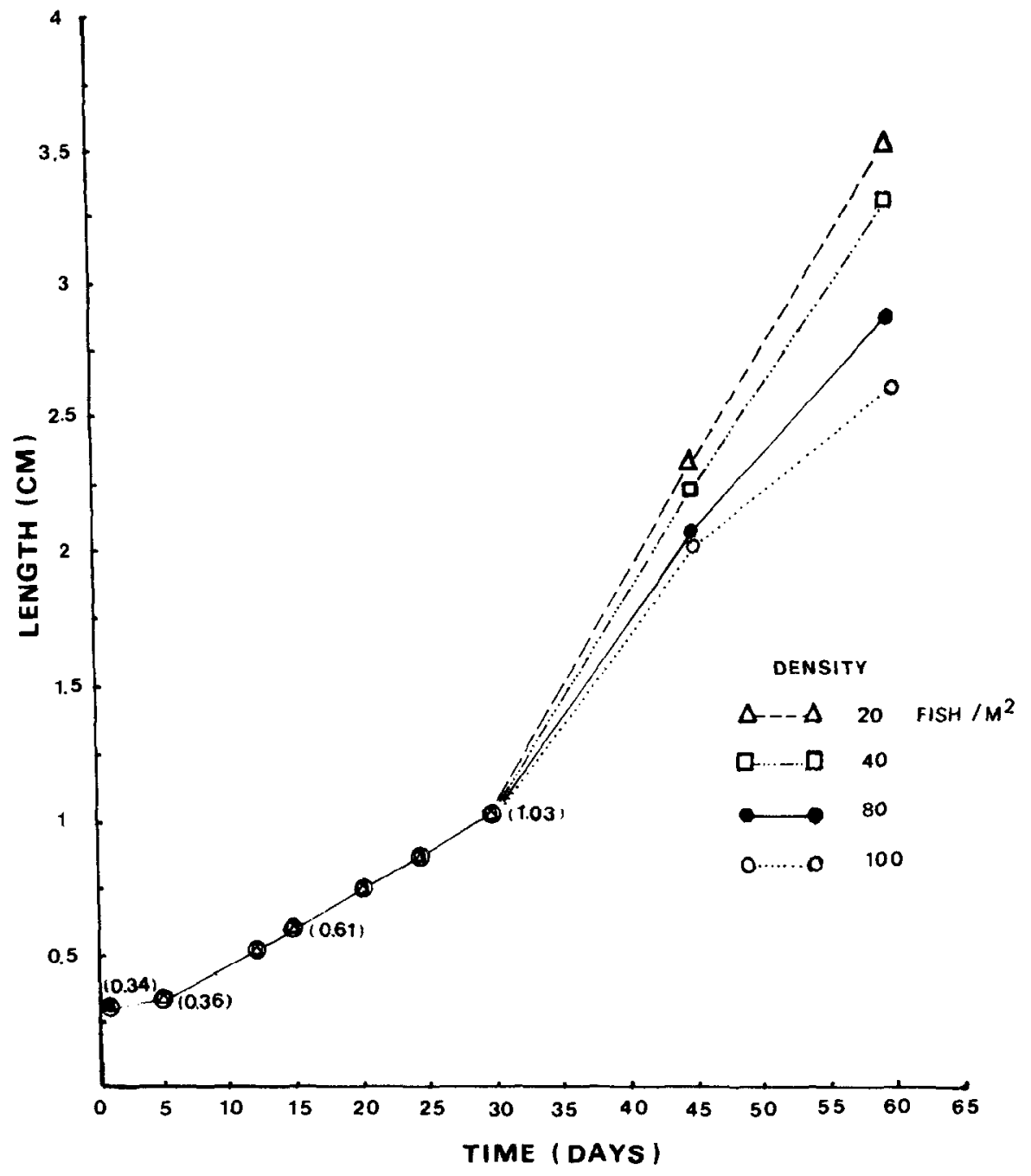

Fig. 2. Growth rate of sand goby fry in two stages during a 60-day culture period. Fry at stage 1 (first 30 days) were all reared at the same density (values in parentheses are the mean lengths of fry at various sampling dates), stage 2 fry were reared at four stocking densities.

trails. At the second rearing phase (30-60 days), fry survival rates ranged from 75 to $100 \%$, and average fish length increased from 1.0 to $2.5,2.9,3.3$ and 3.5 $\mathrm{cm}$ at densities of $100,80,40$, and $20 \mathrm{fish} / \mathrm{m}^{2}$, respectively (Fig. 2 ).

\section{DISCUSSION}

This study confirms that sand gobies are multiple spawners and spawn throughout the year under suitable conditions. Provision of solid substrates 
for egg deposition was essential in the earthen ponds. While there was no direct evidence of fish mortality caused by seasonal $\mathrm{pH}$ and temperature fluctuation, lack of breeding activity during November and December might have resulted from extrinsic factors, such as the pronounced seasonal change in water temperature. The monthly minimum temperature decreased from $28^{\circ} \mathrm{C}$ in the previous months to less than $24^{\circ} \mathrm{C}$ in the November-December period, and the differential of maximum-minimum temperature was $9-11^{\circ} \mathrm{C}$ compared to less than $7^{\circ} \mathrm{C}$ during the spawning period. As brooder conditions and water quality between the two spawning ponds were similar, the difference in production of egg nests (3.3 and 4.4 nests/female in respective 150 and 125 female/pond) may be related to different stocking density. While the optimal stocking density is yet to be determined, the present result shows that it was advantageous to stock fewer adults to achieve greater egg production.

It was estimated that mature female sand gobies $(400-500 \mathrm{~g} / \mathrm{fish})$ produce more than 50000 eggs annually. Despite the relatively large fecundity and high hatching rate, fingerling production was reduced by severe mortality during larval development and during the young post-larvae stage. On the average, it took 3-5 days to complete larval development. Apparently, in the same cohort, larvae that hatched earliest were less developed than those that hatched later, resulting in a lower survival rate for the early hatched larvae (Tan and Lam, 1973 ). Our experiment showed that a majority ( $>80 \%$ ) of the hatchlings did not survive to the post-larval stage. The second vulnerable stage occurred when young post-larvae shifted from endogenous to exogenous food sources. The post-larvae possess two intrinsic features that seemingly contribute to their high mortality. Firstly, because of their minute body size $(4 \mathrm{~mm}$ long) and weak, jerky swimming movements they tend to settle to the bottom, where their relatively passive feeding behavior makes them poor feeders. This results in lower survivorship. Secondly, their small mouth size $(\simeq 0.1 \mathrm{~mm})$ limits the availability of food organisms, because the most common zooplankton species are larger than their mouth openings. The swim-up fry initially feed primarily on egg slurry and live rotifers. Rotifers of mixed species were most commonly cultured to feed the fry; however, goby fry were reported to feed and survive on a mobile colonial phytoplankton species of Pandorina (32-85 $\mu \mathrm{m})$ for a period of 20 days (M. Boonbrahm, personal communication, 1986).

While we have not made detailed observations on fry feeding mechanisms or their selectivity on prey organisms, the large variation in fry survival rates among rearing trials was most likely caused by different population densities of food organisms, particularly rotifers. The density and timing of food organism availability were observed to be the main factors affecting fry mortality in the culture of walleye (Stizostedion vitreum) larvae (Li and Mathias, 1982).

Culture of sand goby fry is still in the preliminary stages and requires further understanding of feeding habits and behavior. Recently, Lam and Reddy (1986) reported that application of thyroid hormone (thyroxine) promoted larval sur- 
vival, growth, and development of several species of warmwater fish. This approach may provide a new avenue leading to greater larval survival rate in sand goby.

\section{ACKNOWLEDGEMENTS}

This work resulted from joint efforts between Royal Thai Department of Fisheries and Collaborative Research Support Program (CRSP/Pond Dynamics) funded in part by USAID Grant No. 4023-G-SS-2070-00. Technical assistance from $T$. Viputhanumas and $V$. Watcharagornyothin was indispensable for accomplishing the experiments.

\section{REFERENCES}

DOF, 1983. Freshwater Fishfarm Production. Royal Thai Department of Fisheries, Bangkok, 73 pp.

Lam, T.J. and Reddy, K., 1986. Role of thyroid hormones in fish larval growth and development. Abstracts of the First Asian Fisheries Forum, Manila.

Li, S. and Mathias, J.A., 1982. Causes of high mortality among cultured larval walleyes. Trans. Am. Fish. Soc., 111: 710-721.

Lin, C.K., 1986. Acidification and reclamation of acid-sulfate-soil fish ponds in Thailand. Proceedings of the First Asian Fisheries Forum, Manila. Asian Fisheries Soc., Manila, pp. 71-74.

Lin, C.K. and Tavarutmaneegul, P., 1985. Culture of freshwater rotifers and chironomid larvae for fish fry feed. Asian Freshwater Fish Culture Symposium, Beijing, China, in press.

Phinal, C., 1980. Breeding of sand goby, Oxyeleotris marmoratus (Blk.). J. Aquat. Anim. Dis., 3: 15-26.

Smith, H.M., 1945. The Freshwater Fishes of Siam, or Thailand. Smithson. Inst., U.S. Nat. Mus. Bull. 188, Washington, DC, 622 pp.

Suwansart, P., 1979. Cage culture of sand goby, Oxyeleotris marmoratus (Blk.) at Nan River. Thai Fish. Gaz., 29: 51-56.

Tan, O.K. and Lam, T.J., 1973. Induced breeding and early develupment of the marble goby (Oxyeleotris marmoratus, Blk.). Aquaculture, 2: 411-423. 